\title{
Sustainability of complex social-ecological systems: methods, tools, and approaches
}

\author{
Animesh K. Gain ${ }^{1,2}$. Carlo Giupponi ${ }^{2}$ • Fabrice G. Renaud ${ }^{3} \cdot$ Athanasios T. Vafeidis $^{4}$ \\ Published online: 17 August 2020 \\ (C) Springer-Verlag GmbH Germany, part of Springer Nature 2020
}

Social-ecological systems (SES) are nested, multilevel systems in which ecological and social elements interoperate through regular bidirectional interactions and feedback loops (Gunderson and Holling 2002; Holling 2001; Folke 2006). They are characterised by complex and dynamic interdependencies, between social and ecological sub-systems (Liu et al. 2015), which remain poorly understood. However, understanding the dynamics of complex SES interactions is essential for supporting both human well-being and the sustainable management of resources (Gain et al. 2019a). Failure to recognise such complex interdependencies and dynamics has led to severe environmental problems (Gain et al. 2019b) and developmental challenges, such as climate change impacts, biodiversity loss, resource scarcity, and resource degradation. The interconnectedness of complex problems cannot be assessed with traditional disciplinary approaches alone. Instead, inter- and trans-disciplinary approaches are required to deal with such sustainability challenges.

Within the last decade, significant progress has been made with respect to analysing SES. Specifically, SES have recently emerged as a prominent analytical framing to investigate pressing sustainability issues in the Anthropocene (de Vos et al. 2019; Rockström et al. 2009). A number of frameworks have been developed to study SES, including the socialecological system framework (SESF) (Ostrom 2007, 2009;

This article is part of the Topical Collection on Sustainability of socialecological systems

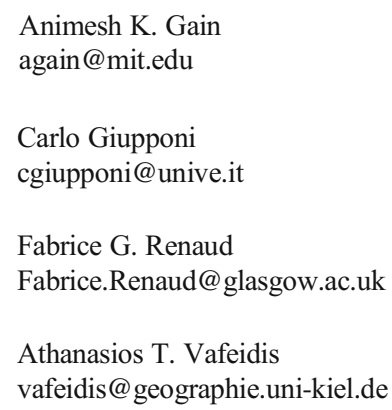

McGinnis and Ostrom 2014), the vulnerability framework (Turner et al. 2003) and the driver-pressure-state-impactresponse (DPSIR) framework (Gari et al. 2015; EC 1999; Lewison et al. 2016). To foster a better understanding of the dynamics and complexity of social-ecological interactions, a variety of assessment methods including both quantitative and qualitative approaches (e.g., system dynamics modelling, network analysis, agent-based modelling, multi-criteria analysis/ indicator-based aggregation, and integrated assessment/ decision support systems/coupled model frameworks) are now available (An 2012; Filatova et al. 2013; Lippe et al. 2019; Belton and Stewart 2002). Despite this progress, the operationalization of the conceptual frameworks through applying innovative methods and tools to allow for the sustainable development of SES is still an active field of investigation.

The goal of this Topical Collection is to analyse the sustainability of SES at different scales by using recently available innovative methods, tools and approaches. The Topical Collection emerges from a 2-day workshop in Kiel, Germany (26-27 September 2018), involving key interdisciplinary researchers in the field of SES. This Topical Collection comprises papers spanning areas from theories to quantitative methods that contribute to analysing multiple sustainability challenges of complex SES at different regional contexts.
1 Environmental Policy and Planning (EPP) Group, Department of Urban Studies and Planning (DUSP), Massachusetts Institute of Technology (MIT), 77 Massachusetts Ave, Cambridge, MA 02139, USA

2 Department of Economics, Ca' Foscari University of Venice, Cannaregio 873, 30121 Venice, Italy

3 School of Interdisciplinary Studies, University of Glasgow, Rutherford/McCown Building, Dumfries DG1 4ZL, UK

4 Coastal Risks and Sea Level Rise Research Group, Department of Geography, Christian Albrecht University of Kiel, Kiel, Germany 
Baggio et al. (2019) study the role of social learning and inter-jurisdictional networks (linking socio-political and ecological processes) in order to reduce biodiversity loss. They present a theoretical multiplex network model that mimics multiple political jurisdictions making decisions affecting species migration across a landscape. Direct application of the model is described based on two cases (i.e., the removal of fences in the Great Limpopo Transfrontier Park, in southern Africa, and cooperation to solve regional environmental dilemmas in Arizona). The results indicate that maintaining heterogeneity in learning and knowledge approaches and sharing this knowledge lead to increasing species coexistence and, hence, reducing biodiversity loss in times of fragmented ecological landscape.

Bodin et al. (2019) investigate how and why preestablished social networks facilitate effective collaborations in addressing natural hazards. Empirically investigating with crisis responders of large-scale wildfires in Sweden and Canada, they analyse factors that shape actors' ability and willingness to form new social ties with other actors. In addition, they also assess the propensity to activate pre-existing social ties. By using social network analysis, they find that pre-existing ties comprised a considerable proportion of all ties. Using exponential random graph models, the results show that actors who are working with (or have previously worked with) a common third actor are more likely to activate pre-existing social ties. They conclude that the tie formation and activation differences can be attributed to diverging organisational contexts varying in their reliance upon selforganising versus command-and-control approaches.

Hossain et al. (2020) present a case of participatory modelling in the Bangladesh delta in which the concept of complex social-ecological systems (SES) is adopted for capturing dynamic properties for long-term sustainability and human wellbeing. Shared conceptual system dynamics (SD) models are developed with stakeholders and feedback loops are identified for the ecological and social sub-systems. Results allow exploring the relationships between water availability with crop, fish, shrimp and forest production. Moreover, they explore the relationships between biophysical thresholds (i.e., river discharge, air temperature and soil salinity) and social impacts, which may put SES resilience at risk and increase the likelihood of regime shifts.

Adams et al. (2020) investigate the relationship between ecosystem services and poverty in different SES of the delta coastal region of Bangladesh. They focus on three dimensions: economic contribution of provisioning ecosystem services to households' livelihood mix, social-ecological systems producing different bundles of ecosystem services, and material wealth versus reported life satisfaction. The approach is a large-scale household survey and variables are analysed with logistic random intercept models. The approach allows characterising, among other things, the linkages between
SES types and life satisfaction (a measurement of subjective well-being) and material poverty.

Ferdous et al. (2020) explore the "protection paradox" in the Jamuna River floodplain in Bangladesh whereby the protection of the coastal floodplain can lead to increases in flood damages due to over reliance on protection and reduced preparedness. Using primary and secondary data on population density, human settlements and flood fatalities, they compare two urban areas and two rural areas with different flood protection levels and find that higher levels of flood protection are associated with higher increase in population density over the past decades as well as assets exposed to flooding. The results of the study indicate that flood mortality rates associated with the 2017 flooding in Bangladesh were lower in the areas with lower protection level, thus highlighting the unintended consequences of structural flood protection and their relevance for the establishing sustainable policies of disaster risk reduction and adaptation to climate change in rapidly changing environments.

Balbi et al. (2020) also focus on the inherent complexities and internal interdependencies of dynamic SESs. In particular, they explore the role of behavioural features of human agents in driving the outcomes in terms of food security, by proposing a game theory model to explore the role of cooperation and diversity at the community level in southern Malawi. The model simulates cropping strategies, by considering cooperation, as driven by other-regarding preferences, and conformation, as the tendency to converge to similar choices, as opposed to differentiation driving to crop diversity. Results show that cooperation is only necessary for community success when the community converges on similar crop planting choices, while differentiation can succeed with or without cooperation. Based on the results, the authors suggest that the sustainability of the whole community can be reached through different pathways and-food-exchange mechanisms within and beyond the system boundaries.

Martin et al. (2020) extend an existing bistability model for shallow lakes focusing on the predator-prey relationship between two fish species by explicitly introducing vegetation as an additional state variable. This is done to understand the social-ecological interactions in lake restoration and specifically to determine the time required to restore lakes from turbid to clear states as a result of restoration measures that operate at different time scales. Restoration scenarios are used to demonstrate that combined measures are effective to restore lake environments while single restoration measures may not achieve a change in the state of the lake. The paper emphasises that balancing short-term improvements and long-term influences on the systems' state is critical.

Lazar et al. (2020) employ an integrated assessment model, the Delta Dynamic Integrated Emulator Model ( $\triangle \mathrm{DIEM})$, to explore the outcomes of four contrasting adaptation trajectories on the southwest coast of Bangladesh. Their results show 
different trade-offs between the four trajectories: embankment rehabilitation reduces flood risk, but at a high economic cost and also enhances waterlogging; planned and unplanned migration combined with limited infrastructure management and governance can result in significant abandonment. On the other hand, building elevation through sedimentation has the potential for increased environmental and economic sustainability but raises equity issues. Despite their results being sensitive to factors such as sea level rise and socio-economic development, they conclude that integrated assessment tools that link the environment, people and policy choices are important for highlighting the complex interactions occurring in a dynamic delta environment and can be used to support informed management, development and adaptation.

For analysing the sustainability of complex social-ecological systems, innovative methods and approaches that are able to account for and represent interactions between the various system components are essential. These approaches are evolving rapidly, supported by the increasing availability of data on physical and socio-economic parameters. In order to support the analysis of social-ecological systems and promote scientific understanding, this Topical Collection brings together eight examples of diverse tools and methods spanning areas from theories to quantitative methods. We hope that the Topical Collection will contribute to the analysis of multiple sustainability challenges of complex SES in different regional contexts.

Acknowledgements AK Gain gratefully acknowledge Marie Skłodowska-Curie grant agreement No. 787419 under the European Union's Horizon 2020 research and innovation programme. The authors would like to acknowledge the participants of the workshop held in Kiel, Germany. The workshop was funded by the cluster of excellence, 'The Future Ocean' (Project Number CP1778).

\section{References}

Adams H, Adger WN, Ahmad S, Ahmed A, Begum D, Matthews Z, Rahman MM, Nilsen K, Gurney GG, Streatfield PK (2020) Multidimensional well-being associated with economic dependence on ecosystem services in deltaic social-ecological systems of Bangladesh. Reg Environ Chang 20(2):42. https://doi.org/10.1007/ s10113-020-01620-x

An L (2012) Modeling human decisions in coupled human and natural systems: review of agent-based models. Ecol Model 229:25-36. https://doi.org/10.1016/j.ecolmodel.2011.07.010

Baggio JA, Schoon ML, Valury S (2019) Managing networked landscapes: conservation in a fragmented, regionally connected world. Reg Environ Chang 19(8):2551-2562. https://doi.org/10.1007/ s10113-019-01567-8

Balbi S, Alvarez-Rodriguez U, Latora V, Antonioni A, Villa F (2020) A game theory model to explore the role of cooperation and diversity in community food security: the case of Southern Malawi. Reg Environ Chang 20(2):63. https://doi.org/10.1007/s10113-02001642-5

Belton V, Stewart TJ (2002) Multiple criteria decision analysis - an integrated approach. Kluwer Academic Publishers, Dordrecht. ISBN: 978-1-4615-1495-4
Bodin Ö, Nohrstedt D, Baird J, Summers R, Plummer R (2019) Working at the "speed of trust": pre-existing and emerging social ties in wildfire responder networks in Sweden and Canada. Reg Environ Chang 19(8):2353-2364. https://doi.org/10.1007/s10113-019-01546-z

de Vos A, Biggs R, Preiser R (2019) Methods for understanding socialecological systems: a review of place-based studies. Ecol Soc 24(4). https://doi.org/10.5751/ES-11236-240416

EC (1999) Towards environmental pressure indicators for the EU. Panorama of the European Union, Theme 8, Environment and energy 1st Edition edn. European Commission, Luxembourg

Ferdous MR, Di Baldassarre G, Brandimarte L, Wesselink A (2020) The interplay between structural flood protection, population density, and flood mortality along the Jamuna River, Bangladesh. Reg Environ Chang 20(1):5. https://doi.org/10.1007/s10113-02001600-1

Filatova T, Verburg PH, Parker DC, Stannard CA (2013) Spatial agentbased models for socio-ecological systems: challenges and prospects. Environ Model Softw 45:1-7. https://doi.org/10.1016/j. envsoft.2013.03.017

Folke C (2006) Resilience: the emergence of a perspective for socialecological systems analyses. Glob Environ Chang 16(3):253-267. https://doi.org/10.1016/j.gloenvcha.2006.04.002

Gain AK, Ashik-Ur-Rahman M, Benson D (2019a) Exploring institutional structures for tidal river management in the Ganges-Brahmaputra Delta in Bangladesh. Die Erde 150(3):184-195. https://doi.org/10. 12854/erde-2019-434

Gain AK, Ashik-Ur-Rahman M, Vafeidis A (2019b) Exploring humannature interaction on the coastal floodplain in the GangesBrahmaputra delta through the lens of Ostrom's social-ecological systems framework. Environmental Research Communications 1(5):051003. https://doi.org/10.1088/2515-7620/ab2407

Gari SR, Newton A, Icely JD (2015) A review of the application and evolution of the DPSIR framework with an emphasis on coastal social-ecological systems. Ocean \& Coastal Management 103:6377. https://doi.org/10.1016/j.ocecoaman.2014.11.013

Gunderson LH, Holling CS (2002) Panarchy: understanding transformations in human and natural systems. Island Press, Washington D.C.

Holling CS (2001) Understanding the complexity of economic, ecological, and social systems. Ecosystems 4(5):390-405. https://doi.org/ 10.1007/s10021-001-0101-5

Hossain MS, Ramirez J, Szabo S, Eigenbrod F, Johnson FA, Speranza CI, Dearing JA (2020) Participatory modelling for conceptualizing social-ecological system dynamics in the Bangladesh delta. Reg Environ Chang 20(1):28. https://doi.org/10.1007/s10113-02001599-5

Lázár AN, Nicholls RJ, Hall JW, Barbour EJ, Haque A (2020) Contrasting development trajectories for coastal Bangladesh to the end of century. Reg Environ Chang 20(3):93. https://doi.org/10. 1007/s10113-020-01681-y

Lewison RL, Rudd MA, Al-Hayek W, Baldwin C, Beger M, Lieske SN, Jones C, Satumanatpan S, Junchompoo C, Hines E (2016) How the DPSIR framework can be used for structuring problems and facilitating empirical research in coastal systems. Environ Sci Pol 56: 110-119. https://doi.org/10.1016/j.envsci.2015.11.001

Lippe M, Bithell M, Gotts N, Natalini D, Barbrook-Johnson P, Giupponi C, Hallier M, Hofstede GJ, Le Page C, Matthews RB, Schlüter M, Smith P, Teglio A, Thellmann K (2019) Using agent-based modelling to simulate social-ecological systems across scales. GeoInformatica. https://doi.org/10.1007/s10707-018-00337-8

Liu J, Mooney H, Hull V, Davis SJ, Gaskell J, Hertel T, Lubchenco J, Seto KC, Gleick P, Kremen C, Li S (2015) Systems integration for global sustainability. Science 347(6225). https://oi.org/10.1126/ science. 1258832

Martin R, Radosavljevic S, Schlüter M (2020) Short-term decisions in lake restoration have long-term consequences for water quality. Reg Environ Chang. https://doi.org/10.1007/s10113-020-01643-4 
McGinnis MD, Ostrom E (2014) Social-ecological system framework: initial changes and continuing challenges. Ecol Soc 19 (2). https:// doi.org/10.5751/ES-06387-190230

Ostrom E (2007) A diagnostic approach for going beyond panaceas. Proc Natl Acad Sci 104(39):15181. https://doi.org/10.1073/pnas. 0702288104

Ostrom E (2009) A general framework for analyzing sustainability of social-ecological systems. Science 325(5939):419. https://doi.org/ 10.1126/science. 1172133

Rockström J, Steffen W, Noone K, Persson Å, Chapin FS, Lambin EF, Lenton TM, Scheffer M, Folke C, Schellnhuber HJ, Nykvist B, de Wit CA, Hughes T, van der Leeuw S, Rodhe H, Sörlin S, Snyder PK, Costanza R, Svedin U, Falkenmark M, Karlberg L, Corell RW,
Fabry VJ, Hansen J, Walker B, Liverman D, Richardson K, Crutzen P, Foley JA (2009) A safe operating space for humanity. Nature 461(7263):472-475. https://doi.org/10.1038/461472a

Turner BL, Kasperson RE, Matson PA, McCarthy JJ, Corell RW, Christensen L, Eckley N, Kasperson JX, Luers A, Martello ML, Polsky C, Pulsipher A, Schiller A (2003) A framework for vulnerability analysis in sustainability science. Proc Natl Acad Sci 100(14):8074. https://doi.org/10.1073/pnas.1231335100

Publisher's note Springer Nature remains neutral with regard to jurisdictional claims in published maps and institutional affiliations. 